\title{
INTELLIGENT STORAGE SYSTEM BASED ON AUTOMATIC IDENTIFICATION
}

\author{
Peter Kolarovszki, Juraj Vaculik \\ University of Zilina, Faculty of Operation and Economics of Transport and Communications \\ Department of Communications \\ Univerzitná str. 1, 01026, Žilina, Slovakia \\ Phone: $(+421) 908227492$. \\ E-mail:peter.kolarovszki@fpedas.uniza.sk,juvac@fpedas.uniza.sk
}

\begin{abstract}
This article describes RFID technology in conjunction with warehouse management systems. Article also deals with automatic identification and data capture technologies and each processes, which are used in warehouse management system. It describes processes from entering goods into production to identification of goods and also palletizing, storing, bin transferring and removing goods from warehouse. Article focuses on utilizing AMP middleware in WMS processes in Nowadays, the identification of goods in most warehouses is carried through barcodes. In this article we want to specify, how can be processes described above identified through RFID technology. All results are verified by measurement in our AIDC laboratory, which is located at the University of Žilina, and also in Laboratory of Automatic Identification Goods and Services located in GS1 Slovakia. The results of our research bring the new point of view and indicate the ways using of RFID technology in warehouse management system.
\end{abstract}

Keywords: RFID technology, warehouse, management, automatic identification, processes

\section{Introduction}

This article describes basic concepts of AIDC technologies related to radio frequency identification technology, its basic components and functions. Describe it in warehouses, storage options and their management through the Warehouse Management System. Further disclosed is a database management system MySQL database, middleware, programming language PHP and a text editor Notepad ++ . The aim of this article is the design and partial realization of the warehouse management system using RFID technology, enabling recording arrival and departure of goods in the warehouse and premises and assigns each item. The paper describes the creation of configuration management warehouse in program AMP 2.

\section{Automatic Identification and Data Capture Technologies}

Identification (Thornton and Lanthem, 2006) processes that rely on AIDC technologies are significantly more reliable and less expensive than those that are not automated. The most common AIDC technology is bar code technology, which uses optical scanners to read labels. Most people have direct experience with bar codes because they have seen cashiers scan items at supermarkets and retail stores. Bar codes are an enormous improvement over ordinary text labels because personnel are no longer required to read numbers or letters on each label or manually enter data into an IT system, they just have to scan the label. The innovation of bar codes greatly improved the speed and accuracy of the identification process and facilitated better management of inventory and pricing when coupled with information systems. RFID represents a significant technological advancement in AIDC because it offers advantages that are not available in other AIDC systems such as barcodes. RFID offers these advantages because it relies on radio frequencies to transmit information rather than light, which is required for optical AIDC technologies. A type of AIDC technologies clearly describes Figure 1.

Like bar codes in an earlier time, RFID is the next revolution in AIDC technology. Most of the advantages of RFID are derived from the reliance on radio frequencies rather than light (as is required 
in optical technology) to transmit information. This characteristic means that RFID communication can occur:

- Without optical line of sight, because radio waves can penetrate many opaque materials,

- At greater speeds, because many tags can be read quickly, whereas optical technology often requires time to manually reposition objects to make their bar codes visible, and

- Over greater distances, because many radio technologies can transmit and receive signals more effectively than optical technology under most operating conditions.

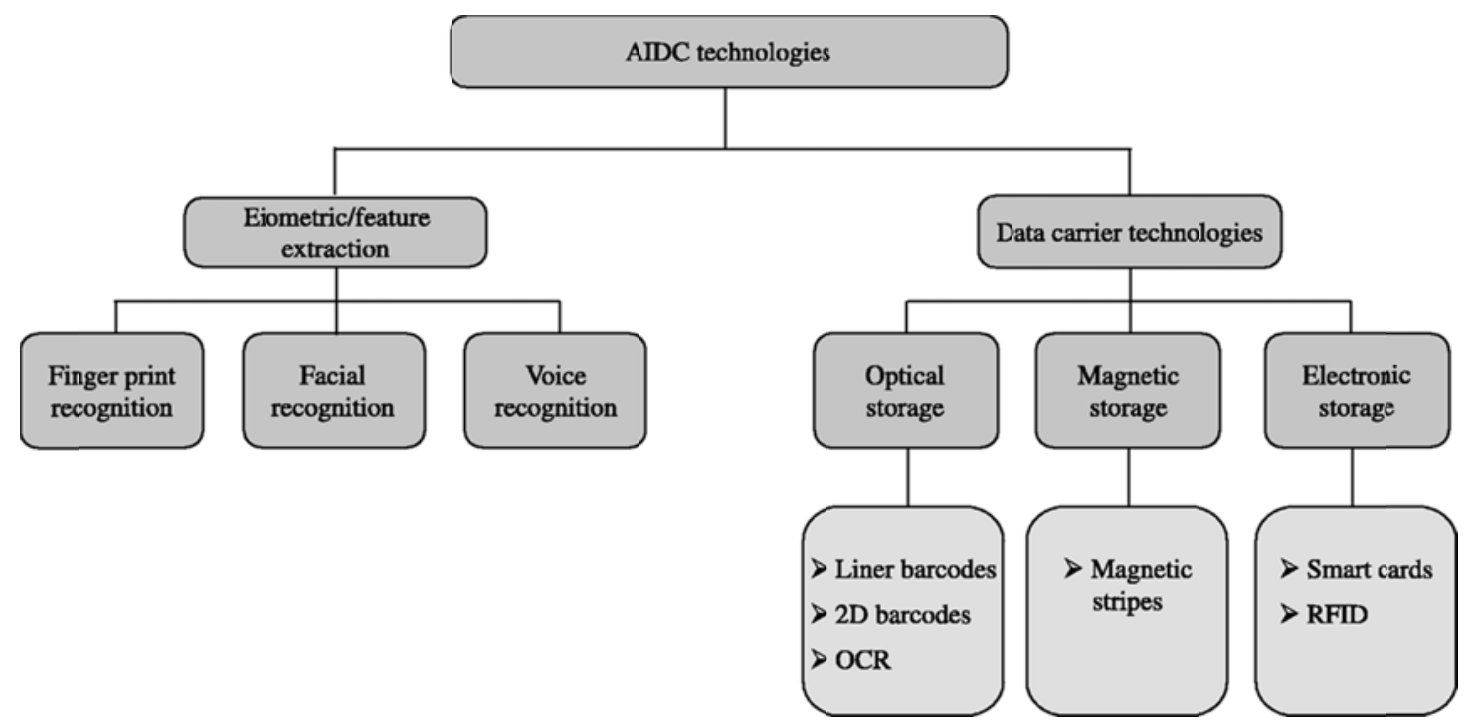

Figure 1. Type of AIDC technologies

\subsection{Radio frequency identification}

Radiofrequency identification (RFID) (Hunt, Puglia, 2007) is a form of automatic identification and data capture (AIDC) technology that uses electric or magnetic fields at radio frequencies to transmit information. An RFID system can be used to identify many types of objects, such as manufactured goods, animals, and people. Each object that needs to be identified has a small object known as an RFID tag affixed to it or embedded within it. The tag has a unique identifier and may optionally hold additional information about the object. Devices known as RFID interrogators (also called readers) wirelessly communicate with the tags to identify the item connected to each tag and possibly read or update additional information stored on the tag. This communication can occur without a line of sight and over greater distances than other AIDC technologies.

\subsubsection{RFID system components}

RFID systems can be very complex, and implementations vary greatly across industries and sectors. For purposes of discussion in this document, an RFID system is composed of up to three subsystems:

- An RF subsystem, which performs identification and related transactions using wireless communication,

- An enterprise subsystem, which contains computers running specialized software that can store, process, and analyze data acquired from RF subsystem transactions to make the data useful to a supported business process, and

- An inter-enterprise subsystem, which connects enterprise subsystems when information needs to be shared across geographic or organizational boundaries.

Every (Kebo, Staša, Beneš, Švub, 2013) RFID system contains an RF subsystiem, and most RFID systems also contain an enterprise subsystem (Figure 2). An RFID systems supporting a supply chain is 
a common example of an RFID system with an inter-enterprise. In a supply chain application, a tagged product is tracked throughout its life cycle, from manufacture to final purchase, and sometimes even afterwards (e.g., to support service agreements or specialized user applications).

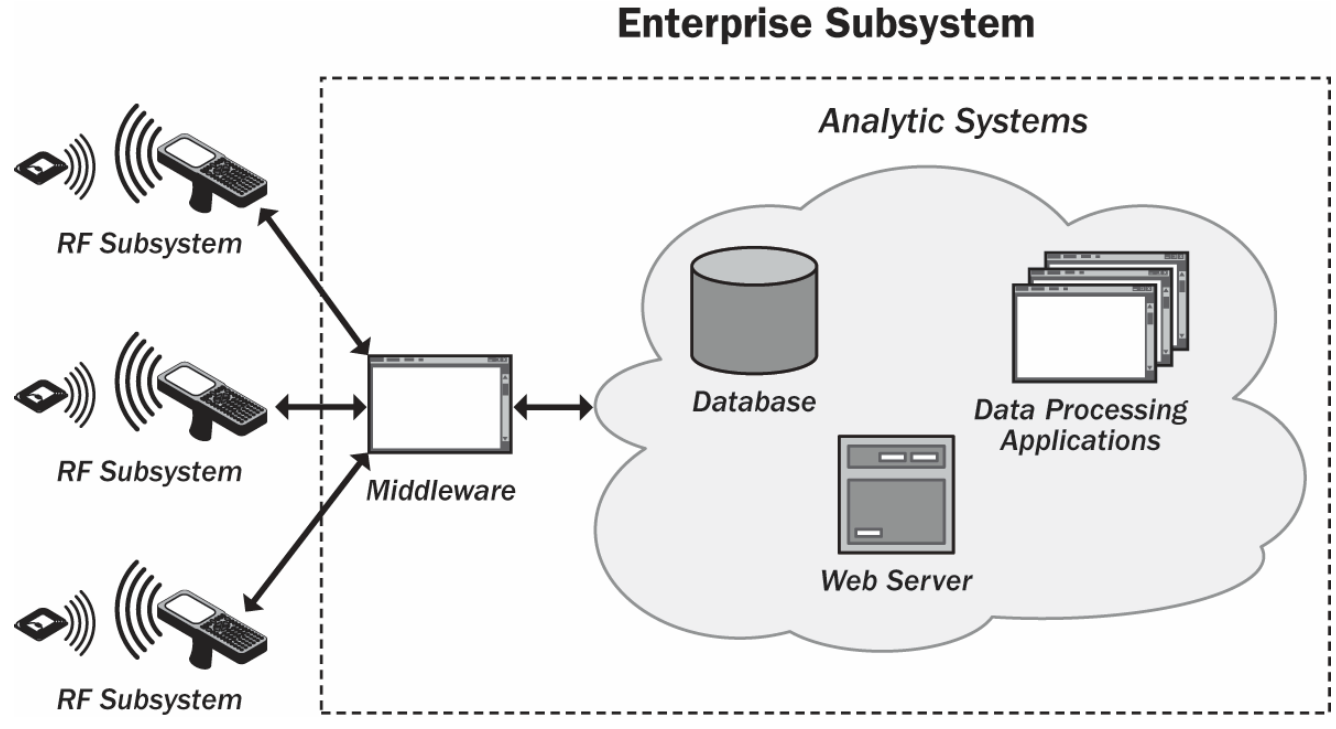

Figure 2. RFID system architecture

\subsubsection{RF Subsystem}

To enable wireless identification, the RF subsystem consists of two components:

- RFID tags (sometimes referred to as transponders), which are small electronic devices that are affixed to objects or embedded in them. Each tag has a unique identifier and may also have other features such as memory to store additional data, environmental sensors, and security mechanisms.

- RFID interrogators (often called readers), which are devices that wirelessly communicate with tags to identify the item connected to each tag and possibly associate the tagged item with related data.

Both the tag and interrogator are two-way radios. Each (Kocur, Machula, Kulda, Vojtěch, 2010) has an antenna and is capable of modulating and demodulating radio signals. Figure 3 shows a simple RF subsystem configuration.

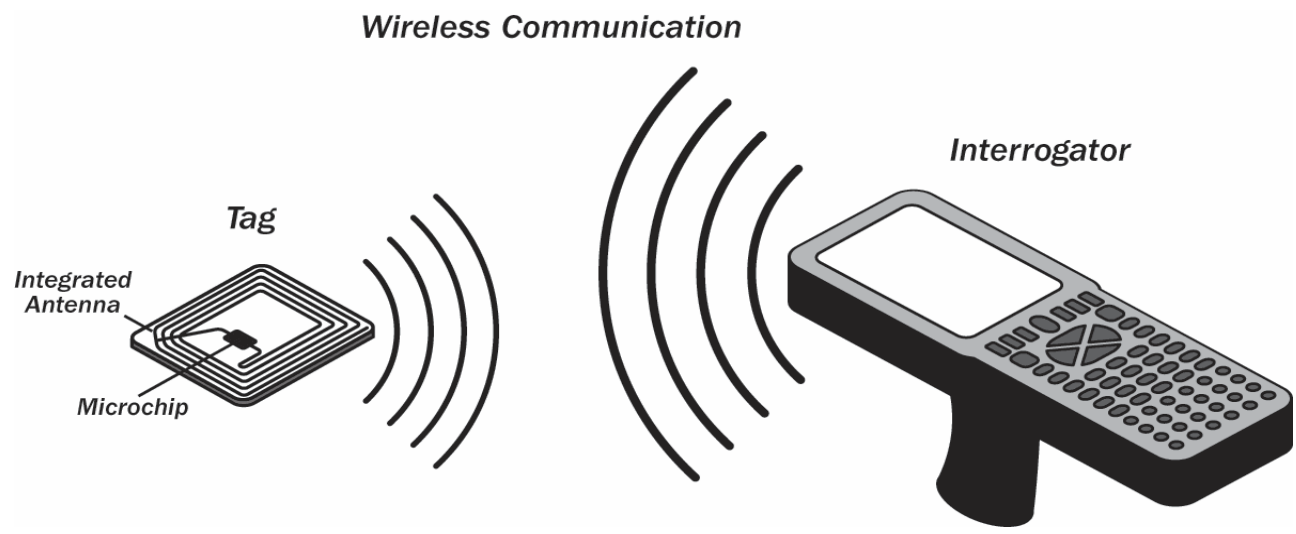

Figure 3. RF subsystem configuration 
An RFID tag (Beneš, Kubáč, Staša, Kebo, 2013) is a small device that can be attached to an item, case, container, or pallet, so it can be identified and tracked. It is also called a transponder. The tag is composed of microchip and antenna. These elements are attached to a material called a substrate in order to create an inlay.

Tags are categorized into three types based on the power source for communication and other functionality:

- Active.

- Passive.

- Semi-passive.

- Semi-active.

\subsubsection{RFID middleware}

Middleware is software that controls the reader and the data coming from the tags and moves them to other database systems. In our cases we have used the Aton AMP middleware. It carries out basic functions, such as filtering, integration and control of the reader. RFID systems work, if the reader antenna transmits radio signals. These signals are captured tag, which corresponds to the corresponding radio signal.

This is a very special software device enabling mutual communication between two and more applications. This device is marked also as a mediator between various application components. The core activity of such devices covers the linking and switching of various different applications or hardware components for exchange, record and data modification purposes. There is a RFID middleware located between reader and server/database or other software device. This can have various functions depending on complexity of the system.



Figure 4. AMP platform

\section{Warehouse Management System}

\subsection{Warehouse management}

The management of a warehouse is the main function of a warehouse management system. On the one hand, these systems keep record of the storage capacity, i.e., the specification of the existing storage bins (location management), on the other hand, of the stored units (inventory management). In addition to this, it should also include several control functions to optimize the storage activities. 


\subsubsection{Warehouse type management}

While the staffs in a manually operated warehouse system is able to independently choose the right conveyor and storage facility owing to their knowledge and experience, in an automatic warehouse management system single elements have to be assigned according to their compatibility. Furthermore, the manual operator fulfills certain tasks intuitively while an automatic system is not able to derive the sequence of work steps, like the loading or unloading of the storage channel according to the FIFO principle, from the instructions.

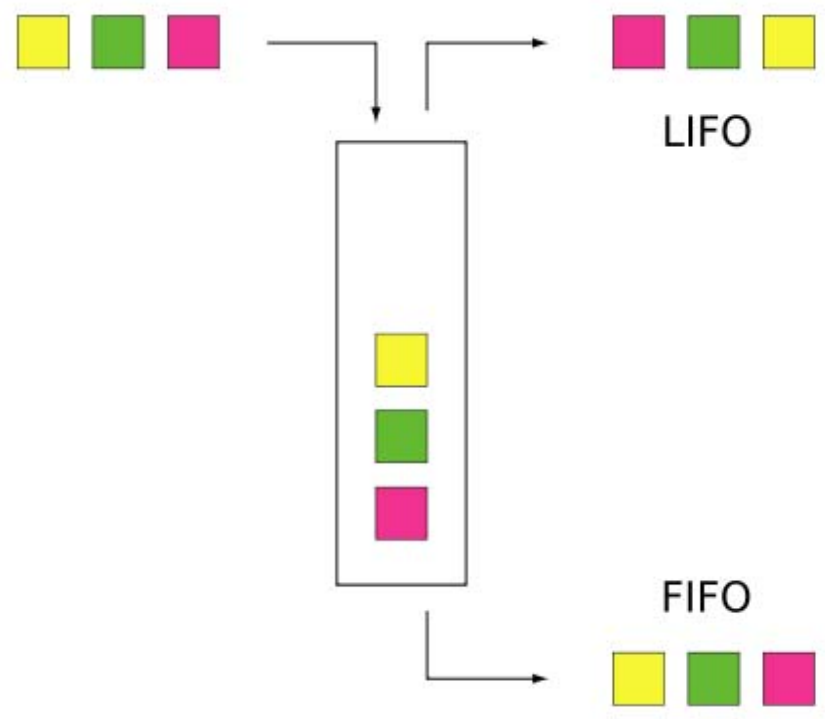

Figure 5. FIFO and LIFO strategy (Klapita and Mašek, 2012)

Some warehouse functions call for the independent generation of orders, e.g., to define restorage or to optimize the gripping time, and thus for the knowledge of the right storage and retrieval operations.

The basis for such optimizations, thus are the stringent classification of the storage and conveyor technology from the informational point of view. For this purpose the warehouse types listed in Table 1 should be defined.

Table 1. Warehouse types

\begin{tabular}{|l|l|}
\hline Description & Parameters \\
\hline Storage bin & Bins, shelves, channels, \\
\hline Access to single locations & Random, stack, LIFO, FIFO \\
\hline Execution & Automatically - manually \\
\hline Storage operation & $\begin{array}{l}\text { Definition of suitable storage facilities (loading } \\
\text { capacity, range, rights) }\end{array}$ \\
\hline
\end{tabular}

\subsubsection{Management of storage bins}

At first (Klapita and Mašek, 2012), the management of storage bins represents the technical warehouse structure, i.e., the specification of the storage bin based on the storage technique (e.g., shelf racks) including the description of the dimensions, loading capacity and position (e.g., shelf coordinates). Some strategies for the assignment of storage bins require such a precise description of storage locations. More flexible storage methods (e.g., floor storage areas) may only need the specification of the areas and coordinates. 
The management of storage bins also includes the management of units stored at a certain location. This includes the entry of goods specific data such as article specification (article number or number of the unit load) as well as the registration and update of the quantities stored in each location.

Status data are required for the control of storages and retrievals. When the storage bin is registered at the identification point, on the one hand, its availability has to be sure, and on the other hand, it is has to be ensured that this location is not assigned twice. For this purpose, different states are assigned with regard to the storage bin which is then blocked or reserved for certain articles or orders.

In case of retrieval, it has to be known if a certain unit is available. To make sure that the chosen unit is assigned to the current order the article status has to be linked to the order. In addition to the storage and retrieval the blocking of stocks or the setting of blocking indicators are an elementary management function used for various operations. These are above all:

- Blocking for storage and retrieval and

- Blocking for certain warehouse operations (e.g., avoid restorage of fragile goods).

The list of all occupied locations, i.e., the representation of the current warehouse status, is called bin status report. The bin status report may also include the type and quantity of articles stored in each bin.

\subsubsection{Quantity management (Inventory management)}

Quantity (Klapita and Mašek, 2012) and inventory management are another logical aspect, which focuses on the registration and update of the quantities of each stored article, sometimes under consideration of the relevant states. The management of goods according to different criteria ( $\mathrm{min} / \mathrm{max}$. stocks) should to ensure the supply and avoid excess quantities. When fixed limits are exceeded or not achieved messages or actions (orders, restorage, etc.) have to be generated.

This function, however, requires a careful control of the stored goods including the allowed storage time and blocking of the article when a certain (expiration) date has been reached. Under certain conditions the respective goods have to be taken out of store to protect other goods.

The main difference to an enterprise resource planning system (ERP), which has similar functions, is the warehouse management, while an ERP system mainly focuses on customers and sales. For this reason, a warehouse management system generally does not contain customer data or prices. Nevertheless, a functioning overall system needs the continuous exchange between WMS and ERP.

\section{WMS Based on RFID Technology}

In our research, we aimed to create a configuration for warehouse management using RFID technology. We will not focus on the hardware but the software part of the essence of the whole application. We have based on the current status of the issue abroad, as illustrated on Figure 6.

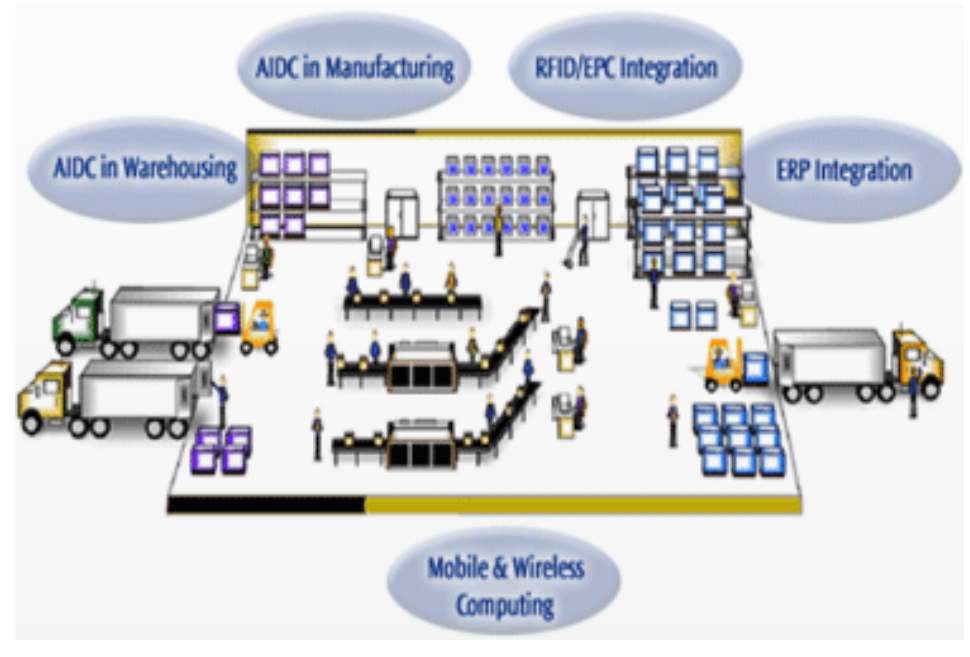

Figure 6. AIDC technologies in WMS 


\subsection{Configuration WMS in middleware AMP 2}

As a software support for our WMS application we used middleware AMP2, which communicates with the tags and readers. The following sections of this chapter will introduce the configuration in this program.

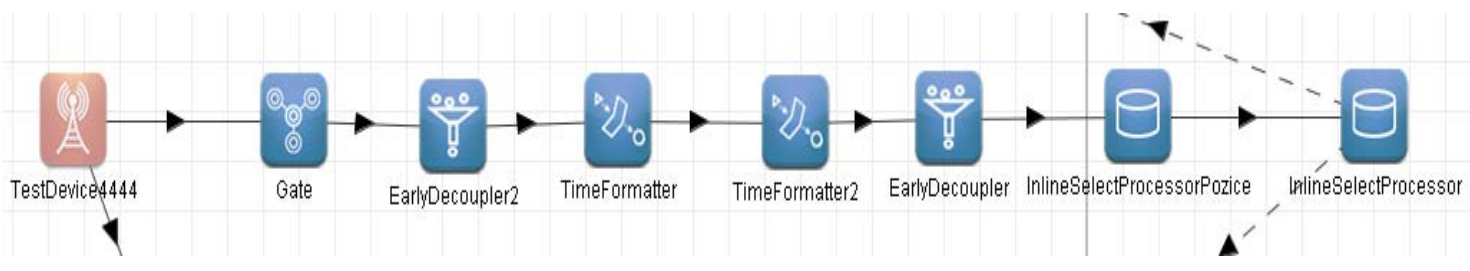

Figure 7. Configuration for tagId generating, filtering, registration time and date

Test Device is used to simulate the transition RFID identifier through the reading point, the configuration settings are assigned tag. Id value 763521473254102154474869. The number represents the EPC code, which clearly indicates that item. Processor Test Device sends this information to the processor GATE.

Gate processor further transmits this information only if the configuration is set to open (default is close). If the Gate is open tagId transmits information to another processor, which is Early Decoupler, his job is to filter out duplicate values.

Subsequently (Lúčan, 2013), the data are sent to the processor Time Formatter, which is used to assign a timestamp to the value tagId. Inline Processor Select Position provides assignment lowest available value of the position of the wireless, so to that number tagId assigned a position in the stock. It is only in this case that is the position of state $=0$, so the position is free. Next in line is again Inline Select Processor, whose task is to compare the value with the value tagId is already registered in the database table, namely it is a table count_store. Depending on whether the value given in the table is or not will be based on the conditions set in the processor branching. In the event that the item is not in count_store branching occurs on Select Inline Processor 3.

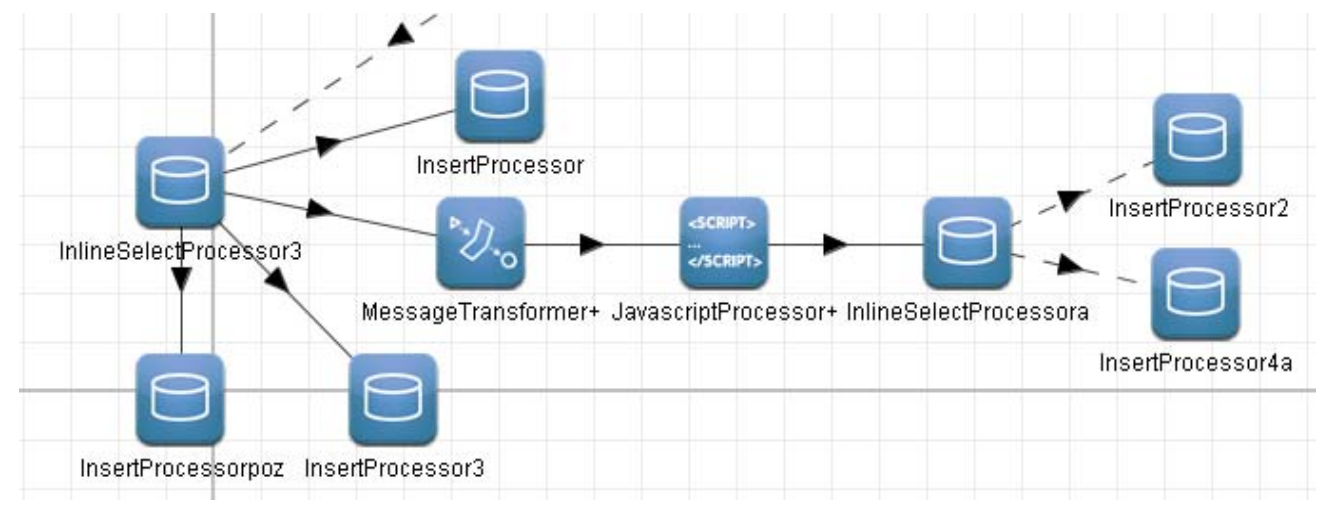

Figure 8. Configuration for writing date into the database (Lúčan, 2013)

Inline Select processor 3 (Lúčan, 2013) receives data, if the condition in Inline Select Processor is not true. Insert Processor insert data into a database table called count_store. Using SQL functions insert are data inserted into the table information about identifier that is tagId. Than assigned him the position, which represents the lowest available value in the table position. Based on this information it is possible to identify a particular product and also determine its specific location in the warehouse. Insert processor poz, updates the position of the table, where the position of the assigned status changes to 1 , which means that the position is occupied.

Another processor, which is used to write data into table is Insert the Processor 3. The processor writes data into the table journal. To journal table are written tagId values, on which it is possible to accurately identify the product, further writes the date and time of receipt of items in storage. Then writes status, which determines whether the product is put away or removed and further down the number of positions at which the product is stored. 
Message Transformer + processor ensure the removal of only certain parts of XPath. In a specific example, the part tagId that is required for the next processor, which is a Java Script. His role is of a specific character string extracted the required number of characters. In our example Java Script processor with Split method is set to remove the part tagId, which represents the EPC code that represents the type of product, thus sending a further modified value.

Inline Select processor selects from a table store the number of items in the column indicating type. Based on the conditions is divided into these processors. If the condition is true, therefore the type of product is already in stock, then increasing the number of pieces of the same type of products to 2 . This operation performs the Insert Processor 2. If that condition is not satisfied, therefore, that type of product is not in stock yet. Insert Processor 4a ensures inclusion of this type to the table named as store. Than is entered the value of id, type, count, position that is the serial number of the product type, actual product type, number of units and assigned position.

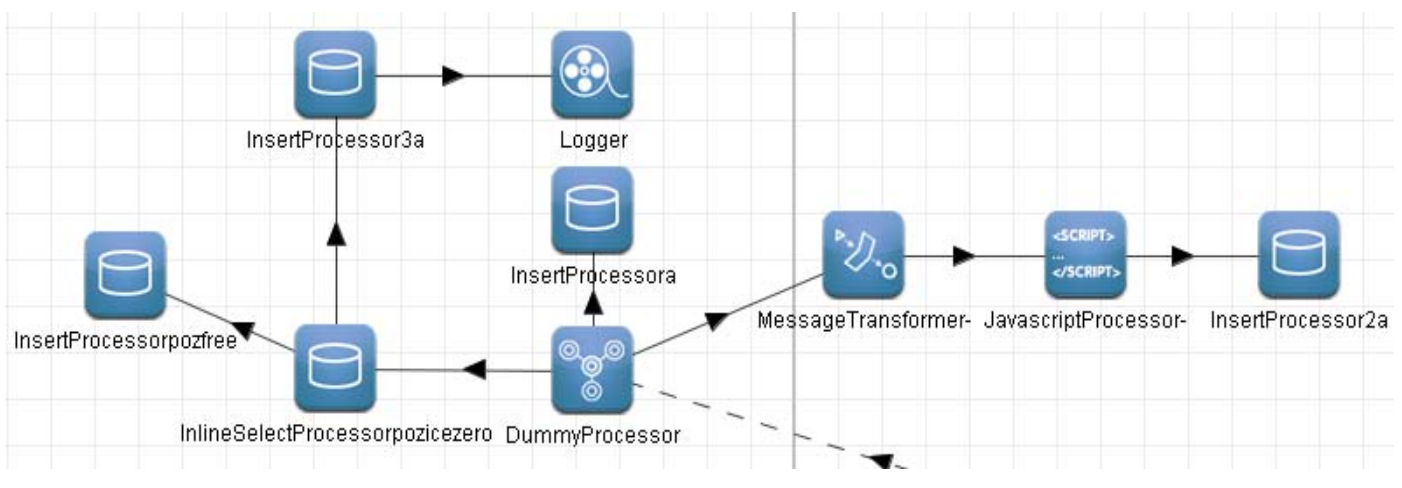

Figure 9. Configuration for removing data from database (Lúčan, 2013)

In (Lúčan, 2013), the event that the item is located in count store branching occurs on Dummy Processor. The identifier with the value tagId gate passes a second time, which implies that it is the direction of the product out of the warehouse (removal of goods). Insert 2 Processor based on the extracted parts tagId update the store table, which will reduce the number of items 1.Insert Processor is used to delete data from a table count_store, removing of these data represents the removal process of goods from the warehouse. Select Inline Processor pozicezero selects a value position from the table count store. Insert Processor pozfree on the basis of information, which obtained from the previous processor, updates the data in the table position. In this case, set the value to 0 , because if the item be removed from storage, frees up the position at which it was located.

The last processor in this tree is Insert Processor 3a, which added information concerning the removal items to the journal table. Write the serial number id, tagId, which represents a particular product, time and date of removal, status. In this case, the 0 , because the item has left the warehouse, and finally the position at which the item is found itself. In this tree configuration is the processor Logger, which shows information about readable identifier to the consol.

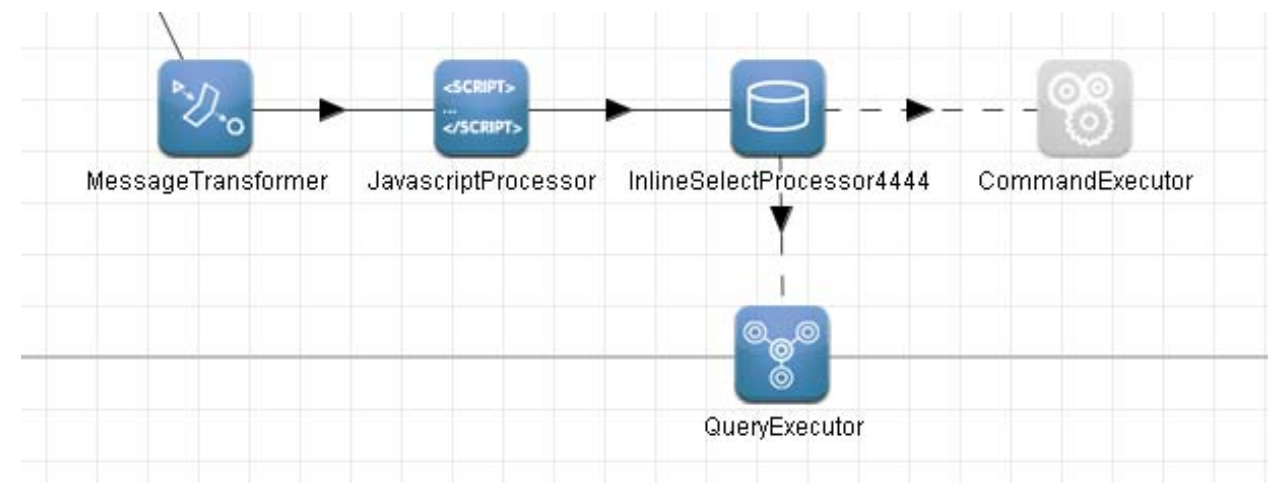

Figure 8. Configuration for the detection of supported items (Lúčan, 2013)

In this tree is tested whether the specified value tagId representing an item in the list of supported products for the store. Whole configuration is shown in next figure. 







\section{Conclusions}

Technology of automatic identification plays a significant role nowadays in all the fields of economics. Regarding the optimisation of supply chains, the bar code technology is utilized for this purpose in a long term. Technology of radio frequency identification is getting more and more popular considering multitude of advantages and therefore it is highly expected, that its application will be extending further into all the fields of economics, including logistics sector. Managing inventory control is possible in several ways. We have chosen the path Coding RFID tags with subsequent creation of applications for warehouse management. The software named as AMP2 met our expectations and we can say that through it is possible to manage stock. In our case it was a model example but experience from abroad shows that more and more logistics companies tend to technologies such as RFID.

\section{Acknowledgements}

This article was created to support project named as:

- $\quad$ Centre of Excellence for systems and intelligent transport II (048/2009/2.1/OP'VaV, Aktivita 1.4) ITMS 26220120050

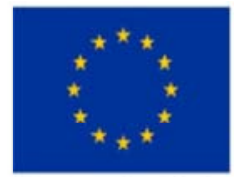

Európska únia





Agentúra

Ministerstva školstva, vedy, výskumu a športu SR pre štrukturálne fondy EÚ

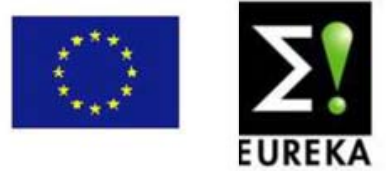

E!7592 AUTOEPCIS - RFID Technology in Logistic Networks of Automotive Industry (RFID technológie v logistických siet'ach automobilového priemyslu)

This article was created in response to tackle a project co-funded by the EU titled "The Quality of Education and Human Resources Development as Pillars of the Knowledge Society" at the Faculty PEDAS at the University of Zilina, ITMS 26110230083 "


Agentúra

Ministerstva školstva, vedy, výskumu a športu SR pre štrukturálne fondy EÚ

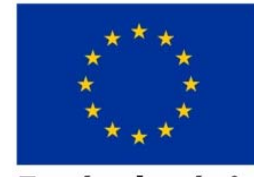

Európska únia

Modern education for the knowledge society / project is co-financed by the EU

\section{References}

1. Beneš, F., Kubáč, L., Staša, P., Kebo, V. (2013) RFID and Augmented Reality. In: Proceedings of the $14^{\text {th }}$ International Carpathian Control Conference (ICCC), Rytro, Hotel Perła Poludnia, Poland, May 26-29. Vienna: IEEE, pp. 186-191.

2. Bolarín, F.C., Frutos, A.G., Lisec, A. (2011) Assessing the impact of prices fluctuation on demand distortion within a multi-echelon supply chain. Promet-Traffic-Traffico. 23(2), pp. 131-140.

3. Hunt, V., Puglia, A., Puglia, M. (2007) RFID: A Guide to Radio Frequency Identification. New Jersey (USA): John Wiley \& Sons, Inc., 201 p. 
4. Kebo, V., Staša, P., Beneš, F., Švub, J., (2013) RFID Technology in Logistics Processes. In: Proceedings of the $13^{\text {th }}$ International Multidisciplinary Scientific GeoConference SGEM, Albena, Bulgaria.

5. Kendra, M., Lalinská, J., Čamaj, J. (2012) Optimization of transport and logistics processes by simulation. In: ISTEC; Proceedings of the $3^{\text {rd }}$ International Science, Technology and Engineering Conference, Dubai, United Arab Emirates (UAE), December 13-15, 2012, pp. 886-892. [Online]

6. Klapita, V., Mašek, J. (2012) Processes solution in the warehouse by the queuing theory application. In: Horizons of Railway Transport: scientific papers (pp. 64-6), volume 3, no. 1. ISSN 1338-287X

7. Kocur, Z., Machula, V., Kulda, J., Vojtěch, L. (2010) Analysis of Influence of Disturbance Level on Data Transmission in Wireless Networks. In TSP 2010 - the $33^{\text {rd }}$ International Conference on Telecommunications and Signal Processing. Budapest: Asszisztencia Szervező Kft., pp. 292-296.

8. Kolarovszká, Z. Fabuš, J. (2011) IT service management in conjunction with the universal postal service in Europe. In: Postpoint 2011, the $9^{\text {th }}$ International Scientific Conference; International meeting of postal administration representatives, university educators and researches, Žilina, Slovakia, September 19-20, 2011. Žilina: University of Žilina, pp. 114-122.

9. Lúčan, J. (2013) Possibilities of warehouse control through by RFID, Diploma thesis, Žilina, 2013, University of Žilina. Faculty of Operation and Economics of Transport and Communications; Department of Communications.

10. Madleňák, R., Švadlenka, L. (2009) User Acceptance of Internet advertising in Czech Republic [Akceptace internetové reklamy uživateli v České republice]. In: Economics and Management: [Ekonomie a management = vědecký ekonomický časopis], volume 12, no. 1, pp. 98-107. ISSN 1212-3609.

11. Maslaric, M., Groznik, A., Brnjac, N. (2012) Distribution channel reengineering: A case study. Promet-Traffic-Traffico, 24(1), pp. 35-43.

12. Thornton, F. \& Lanthem, Ch. (2006) RFID Security. Rockland (MA, USA): Syngres Publishing, Inc., 229 p.

13. Vojtěch L., Neruda M. (2010) Application of Shielding Textiles for Increasing Safety Airborne Systems - Limitation of GSM Interference. In: The Ninth International Conference on Networks (ICN 2010). Los Alamitos: IEEE Computer Society, pp. 157-161. 